\title{
ECONOMIC MEASUREMENT OF OPTIMAL CITY SIZE: THE CASE OF WEST SUMATRA, INDONESIA
}

\author{
Sjafrizal, Suhairi, Winarno, Taosige WAU \\ Andalas University, Padang, Indonesia
}

\begin{abstract}
This is an empirical study of economic measurement of the optimal size of seven cities in West Sumatra region, Indonesia. The empirical findings are quite interesting since the calculated optimal city size does not result in a single measure as mostly previous studies found, but they vary in accordance with the economic approaches used. The optimal city size measured by using the maximum profit approach would have been larger in size compared to those measured by the minimum cost and maximum net benefit approaches. Meanwhile, the cities measured by using the maximum net benefit have larger size than those of the minimum cost. Unlike previous studies, the measurement of optimal city size in this study is performed in terms of population density rather than the total population, in order to consider the influence of land area to the optimal city size. Moreover, by using the population density, the optimal city size becomes a relative index which enables us to compare it with the related size in other regions.
\end{abstract}

Key Words: urban growth, optimal city size, population density, economic measurement, West Sumatran cities.

\section{Introduction}

The general phenomenon of the national demographic trend, both in advanced as well as developing countries, is characterized by high rates of urbanization. The same thing also occurs in Indonesia, including the West Sumatra region, where about fifty years ago more than $75 \%$ of the population lived in rural areas, while now more than half of the population lives in urban areas. Such an increased urbanization rate makes the urban population growth to advance relatively fast, resulting in a very high total population in some cities. However, if the total urban population is too large (over-urbanization), several negative impacts may arise and influence the city's welfare conditions. Such negative impacts include: high unemployment and poverty rates, increased traffic congestions, spread-out slump areas and increased urban criminality. This phenomenon arises the question of how big the urban population size should be in order to satisfy the government as well as the community's preferences?

The optimal city size refers to a suitable size of the city's population under certain economic, social or environment conditions. This study focuses only on the optimal economic conditions to achieve good governance as well as the society development objectives. With respect to economic objectives, the analysis in this study focuses on three major aspects: the minimum cost, the maximum net benefit and the maximum profit. These three economic criteria are important for formulating the urbanization policy to avoid the possibility of over-urbanization which may create some negative impacts to the economic and social life of the city. Moreover, it has also some implications on the long-term city development directions as well as on its environmental protection. The city size measurement in this study used the population density as a determining variable rather than the total population as previous studies did, in order to consider the influence of land area on the optimal city size.

The main objective of this study is to provide an empirical measurement of the optimal city size 
from an economic approach. This analysis is considered important in two main aspects: first, it provides the analysis of the optimal city size from 3 economic points of view such as the minimum costs, the maximum net benefit and the maximum profit, which have some policy implications. The other existing studies, such as Hitzschke (2011), Camagni et al. (2013) and Kim et al. (2014), mostly concentrated on the cost, benefit and efficiency approaches, but omitted the maximum profit approach. Second, following Harris and loannides (2000), this study provides the measurement of the optimal city size based on the population density rather than on the total urban population in order to be able to consider the influence of the large variations in the geographical area of the city. This may be considered as an alternative measurement of the optimal city size since most of the past studies measured it based on the total urban population.

\section{Survey of Related Literature}

It is reasonable enough to say that Alonso (1971) was the famous scholar who provided a pioneering theoretical work on the analysis of optimal city size from the economic point of view. He raised an interesting and challenging research problem related to the question of "how big is too big" and "how big is big enough". Such a question is interesting because it creates a particular analysis for urban economic growth and it provides some important policy implications with respect to urban strategic development as well as urbanization control. Some years later, Richardson (1978) extended the theory with a more realistic analysis by changing all the curves to non-linear forms, although the basic idea remains the same. These two theories are used in this study as theoretical framework for measuring the population number of the optimal city size for each economic approach. Moreover, this theoretical framework is also used to test the Alonso-Richardson hypothesis on the rank order for each optimal city size calculated in relation to its economic orientation.

The main idea within the Alonso-Richardson theoretical framework is to analyse the optimal city size from an economic point of view. In this case, the measurement of optimal city sizes focuses on three economic approaches: i.e. minimum average cost, maximum net benefit and long-run maximum profit. The long-run maximum profit is an economic condition where the profit is zero. These three approaches give different measurements of the optimal city size due to different economic objectives. The minimum cost approach measures the optimal city size based on the criteria of the minimum average cost of the city operational management. This approach may be relevant to objectives of the local government to minimize the use of the national budget. The net benefit approach, on the other hand, measures the optimal city size in terms of the difference between the total benefit provided for the inhabitants with the total operational cost spent by the city administration. This approach may be interesting for the society objectives to maximize the social welfares. However, the maximum profit approach measures the optimal city size based on the criteria of the equalization of marginal cost and marginal benefit. This approach may be suitable for the city businessmen who seek maximum profits for their business activities.

Moreover, this theoretical framework also includes an interesting hypothesis that the optimal city measured based on the long-run maximum profit approach would have a larger size than those measured based on the maximum net benefit. Furthermore, the optimal city size measured based on the maximum net benefit would have a larger size than those measured based on the minimum cost approach (Table 1). Such a variation of the optimal city size is also closely related to the objectives of each approach. The city local government usually prefers a smaller city in order to minimize the per capita local budget. The inhabitants, on the other hand, usually prefer to have medium sized cities in order to avoid the negative impacts of over-urbanization. But, businessmen usually prefer large city sizes to get bigger effective demand for their own business activities. We may call this preposition as the AlonsoRichardson hypothesis which will also be empirically tested in this case study of the West 
Sumatra region in Indonesia.

As indicated in Figure 1, there exists four optional curves as basis of analysis representing the Average Cost $(A C)$ and Marginal Cost $(M C)$ for operating the city, as well as the Average Benefit $(A B)$ and Marginal Benefit $(M B)$, resulting from the economic activities in the cities. Based on the shape of these four curves, there exist several points in the horizontal line which have important economic measurements for the optimal city sizes. First, point $P_{a}$ represents an optimal city size at minimum average cost. Second, point $P_{b}$ indicates the optimal city size at maximum average net benefits conditions where the difference between $A B$ and $A C$ is the largest. Third, point $P_{c}$ refers to the optimal city size at the long-run maximum profit condition where $A C=A B$. These three important points provide different methods for calculating the number of people at optimal city sizes with different results.

The Alonso-Richardson optimal city size model presented in Figure 1 is quite interesting in three aspects: First, the analysis provides the optimal city size estimations using the three standard microeconomic analyses. This may answer the Camagni et al. (2013) findings that the optimal city size may not be a single measure. Second, the optimal city size in this study uses the population density $(P D)$ rather than the total city population as measurement. Such a measurement is important to take into account the large variation in the city area which also determines the optimal city size. Moreover, the measurement of optimal city size based on population density would have some implications with respect to transportation, housing and environment that are important elements of urban growth. Third, it has some important policy implications for the city development orientation and urbanization control. Therefore, it seems to be useful to make an empirical study for the case of West Sumatra cities to measure the optimal city size as a basis for the urban policy formulation.

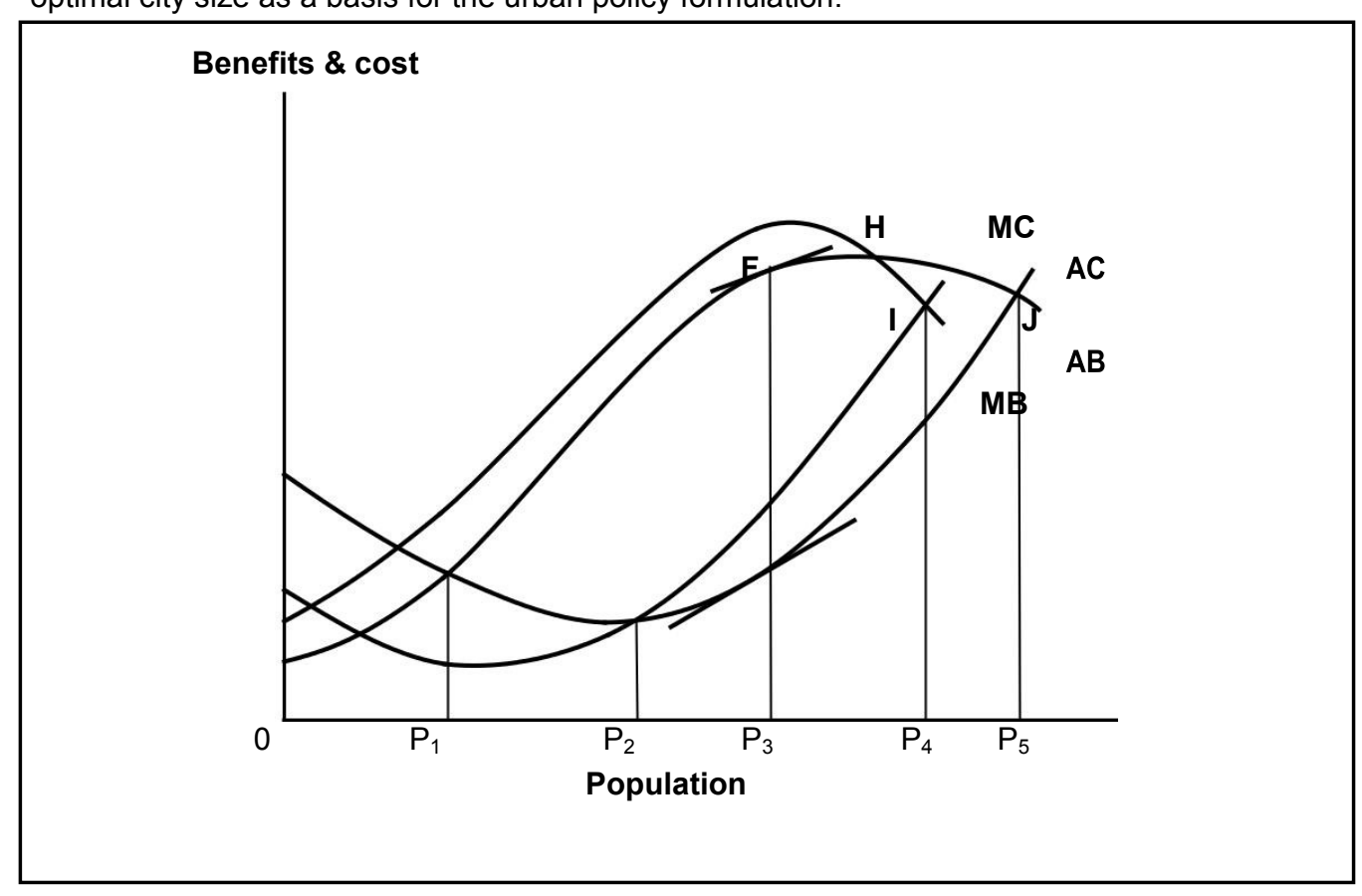

Fig. 1 - Optimal City Size in the Alonso and Richardson Model 
A more formal formulation of the optimal city size was introduced by Arnott (1979) by using the spatial structure and utility maximizing frameworks. He developed a spatial theory of the optimal city size based on the residential location theory. Attention is focused on the necessary conditions for the optimal city size which specifies the relationship between the economic aggregates in the city. Moreover, Arnott and Stiglitz (1979) included variables of land rent and expenditures for the local public goods to the model. On the other hand, Begovic (1991) provides an alternative to the economic approach of the optimal city size by introducing the agglomeration as an explaining variable. The main argument was that the size of a city is mainly determined by the existence of agglomeration economies which encourage economic activities as well as manpower to stay in particular urban areas. Such movements of economic activities and man power will also encourage population to move to that city, which makes its total population to increase faster. The estimation of the optimal city size in this study was based on the linear quadratic regression between the city agglomeration economies and its total population.

The above theoretical framework measures the optimal city size in terms of the total population regardless the city's land area. Such a measurement may not exactly true because the size of the land area would also influence the measurement of the optimal city size. By using the population density as explanatory variable, Harris and loannides (2000) statistically proved that population density influenced significantly the metropolitan productivity, and hence the optimal city size. This suggests that a more relevant measurement of the optimal city size is by using the population density in order to take into account the influence of the size of land area, and our present study also follows this idea.

There are several interesting points related to the recent studies on the measurement of the optimal city size conducted in the last five years. Hitzschke (2011) measured the optimal city sizes of German Cities from the efficiency perspective. He used the Data Envelopment Analysis (DEA) as the method of measuring the production efficiency of cities in terms of scale efficiency. The optimal city size is determined by the maximum point of the quadratic functional relationship between scale efficiency and the total city population size. In this case the optimal city sizes are measured for four geographic areas: West, East North and the Southern part of the country. The empirical findings indicated that the optimal city size for the German cities is around 200000 people, which is relatively close to the average values of the current actual population size of German cities.

On the other hand, Yarmohammadian et al. (2012) estimated the optimal and sustainable size of metropolitan cities in Iran and gave a separate estimation for each city. Following Begovic (1991), this study used agglomeration as the main factor affecting urban growth although, at the same time, it also creates some negative impacts with respect to environmental problems. The optimal city size in this study was estimated for four metropolitan cities in Iran by using the so called surplus function including the pollution externalities. Interestingly, the findings showed that cities in Iran would be overpopulated to the access of $71 \%$ of its optimum size and it has also exceeded its sustainable size by five percent.

Mizutani et al. (2012) measured the optimal city size based on cost and benefit, but also considering social costs related to pollution as an important component of cost structures. The main purpose of this study was to estimate the optimal city size for attaining the total surplus defined as the difference between the total benefit and total cost. The measurement method used in this study was the log-linear cross-section regression using the data set of Japanese metropolitan areas for the year of 2000. This study concluded that the optimal (ideal) cities are those which have smaller populations, in order to maintain the environmental quality. However, it is realized that some other factors should be considered in order to have better measurements. 
Camagni et. al (2013), on the other hand, measured the optimal population sizes of 59 European cities by using the urban cost and benefit as determining variable in the method of measurement. Moreover, this study also included some additional regional variables such as environment quality, urban form and inter-urban cooperation networks. It was also suspected in the study that the difference between the actual urban population size and the predicted optimal (equilibrium) size may explain the efficiency orientation of government policies. Moreover, they also found that other measurements of the optimal city size by using the marginal cost and marginal benefit as well as its own cost were abandoned. The results in this study allow the identification of the city specific equilibrium size. Interestingly, this study also concluded that the difference between the actual urban population and the equilibrium one predicted by the model can be explained by the good or bad governance of the city management performances.

Kim et al. (2014) have studied the optimal city size in South Korea by using the dynamic Interregional Computed General Equilibrium (ICGE) as the method of estimation. Unlike the above two studies, the main objective was to find the optimal urban size to maximize the national economic growth by using the cost and the benefit of urban economic activities in terms of added industrial value. The empirical findings of this study indicated that the national per capita income would be maximized if the optimal size for the South Korean cities reached the percentage of urban population (urbanization rate) of about $39 \%$ on the short term and $35 \%$ on the long-term. However, the government seems to be likely to provide incentives to maintain the optimal urban size at about $40 \%$.

Marques et al. (2015) estimated the optimal size of the Tasmanian local government by using a non-parametric technique on the share of input Data Envelopment Analysis (DEA) to maximize the efficiency of local government. The author indicated that the principal advantage of this technique is that it not only provides an overall estimate of efficiency but it also allows for the estimation of 'partial efficiencies' and 'cost shares' when one input is shared among multiple outputs The result of the study indicated that water supply and sewage services were efficient while the activities related to community health and safety system needed improvement. However, the elimination of these inefficiencies would result in greater cost saving for the Tasmanian local government.

Burnett (2016) conducted a study on the optimal city size of a medium city size in Fort Collin, Colorado, the United States by using the CGE model. This study statistically tested the hypothesis of the inverted-U of real income per worker within the optimal city size by using pecuniary externalities given the unequal distribution of land and capital income to resident households. The findings show that household distribution is skewed towards upper income households of overpopulated cities. The policy implications of this study suggested that urban sprawl, commuting increase, and export oriented retail growth reduce overpopulation, leading to efficiency gains, as export growth does for the services and the total factor productivity growth for manufacturing.

\section{Methodology}

Referring to the Alonso-Richardson model, the measurement of the optimal city size is based on the city total population. Such a measurement actually has a weakness because it does not take into account the large variation in the city land areas. The optimal city size may tend to be larger if the city has a larger land area than those cities with smaller land areas. Since the population density is a relative index than such a measurement of the optimal city size, it may be compared with the similar studies in other regions or countries. Therefore, a more adequate measurement of the optimal city size is in terms of population density rather than the total population as done by Hitzschke (2011) and Camagni et al. (2013) in the previous studies. Considering such a weakness, this study measures the optimal city size based on population 
density that is the total city population divided by the total land area.

Before the optimal city size can be calculated, it is needed to estimate some regression equations on the relationship between each economic variable with the population density of the city. Given the theoretical framework mentioned above, we need the estimation of two functional forms: the Average Cost Function and the Average Benefit Functions. The Average Cost is measured in terms of total operational cost of the city per unit of population. Similarly, the Average Benefit is measured in terms of per capita Gross Domestic Regional Product (GRDP) of the city in which the value of products and services are produced by the city. GRDP is used as proxy for the benefit of the inhabitants since the people need product and services to satisfy their needs. Moreover, GRDP may be also used as proxy for employment availability in the city which is also necessary for the life of the inhabitants.

Since the available data collected is only for 14 years, the measurement of those two curves should not be performed by using the time series method because of the lack number of observations. Due to such data conditions, the estimation of those two curves was performed in terms of pooled data system that is the combination of time series and the cross section method of regression. The data comprise with the existing of 7 cities in the West Sumatra region, and the available time series data for 14 years. However, there were 3 missing data because the city of Pariaman was established in 2004. Therefore, the number of observations in the regression estimation are 95 which seems to be rather sufficient to comply the necessary statistical requirements.

The optimal city size from the economic point of view could be estimated using 3 approaches. First, the Minimum Cost Approach, by estimating the optimal city size at minimum average cost $(A C)$ point. Second, the Net Benefit $(N B)$ Approach by estimating the optimal city size at the point where the difference between the average benefit $(A B)$ and the average cost $(A C)$ is maximum. Third, the Maximum Profit Approach, by estimating the optimal city size when the marginal benefit is equal to the marginal cost. Each approach would have its specific curve derived from the Alonso-Richardson theoretical framework described earlier. However, considering Harris and loannides (2000), this study uses population density (PD) instead of total population as the explanatory variable to take into account the influence of land areas into the measurement of optimal city size.

To be able to estimate the optimal city size based on the minimum cost approach, we have to estimate the Average Cost Function first, by using the combination of time series and the cross-section regression (pooling data system) to increase the number of observations. Data used are in the period of 2001-2014 for 7 cities. This period was selected because the Indonesia government implemented the fiscal decentralization policy which started in the year of 2001 and it has significantly changed the urban fiscal structure in Indonesia. The Average Cost Function to be estimated is the function of the city population density $(P D)$ and it is represented in the quadratic form as it follows:

$$
A C_{i t}=\alpha_{o}+\alpha_{1}(P D)_{i t}+\alpha_{2}(\mathbb{Z} P D) \rrbracket_{i t}^{2}+e_{i t}
$$

where $i$ is city and $t$ is time. Coefficient of ${ }^{\alpha_{i}}$ is the regression coefficients and ${ }^{e_{t}}$ is the error terms. To be able to get the minimum point, it is expected that the coefficient of $\alpha_{2}$ has to be of negative sign and the coefficient of $\alpha_{2}$ has to be positive. Given this regression results, the optimal city size can be calculated by taking the first derivative of equation (1) and equated to zero to get the following optimal city condition for the minimum cost approach: 


$$
P_{m c}=-\alpha_{1} / 2 \alpha_{2}
$$

As mentioned above, estimating the optimal city size based on the maximum net benefit approach can be computed by the largest difference between the Average Benefit $(A B)$ and the Average Cost $(A C)$ curves. For this purpose, at the beginning, we have to formulate the $A B$ curve within the quadratic form and also the population function, as it follows:

$$
A B_{i t}=\beta_{o}+\beta_{1}(P D)_{i t}+\beta_{2}(P D)_{i t}^{2}+e_{i t}
$$

To be able to get the maximum point, it is expected that the coefficient of $\beta_{\mathbf{1}}$ to be of positive sign and the coefficient of $\beta_{\mathbf{2}}$ has to be of negative sign. By taking the slope of the AB curve in equation (2) and the $A C$ curve in equation (1) and setting both of them to be equal, then we have the following optimal condition:

$$
\beta_{1}+2 \beta_{2}(P D)_{i t}=\alpha_{1}+2 \alpha_{2}(P D)_{i t}
$$

Furthermore, by solving the equation (4) with respect to $P^{D_{i t}}$ we have the formula to calculate the optimal city size using the net benefit approach ${ }^{P_{N B}}$ as it follows:

$$
\left.P D_{n b}=\llbracket \frac{\left(\beta_{1} \rrbracket \llbracket-\alpha_{1}\right)}{\left(2 \alpha_{2}+2 \beta_{2} \rrbracket\right.}\right)
$$

The necessary condition to get the optimal city size based on the Long-run Maximum Profit Approach where the profit is zero is when the average cost is equal to the average benefit $(A C=A B)$. Given this condition, by equating the average cost in equation (1) and the average benefit in equation (3), we have the following equation:

$$
\alpha_{o}+\alpha_{1}(P D)_{i t}+\alpha_{2}([P D)]_{i t}^{2}+=\beta_{o}+\beta_{1}(P D)_{i t}+\beta_{2}(P D)_{i t}^{2}
$$

Solving the equation (6) with respect to the population density $(P D)$, we have the following measurement of the optimal city size, as it follows:

$$
P D_{m p}=\frac{\left(\beta_{1}-\alpha_{1}\right) \pm \sqrt{\left(\alpha_{1}-\beta_{1}\right)^{2}-4\left(\alpha_{0}-\beta_{0}\right)\left(\alpha_{2}-\beta_{2}\right)}}{2\left(\alpha_{0}-\beta_{0}\right)}
$$

Equation (7) would have two values, with either positive or negative results. Since the value of population density is never negative, we use the positive result as calculated for the optimal city size based on the long-run maximum profit approach.

\section{Highlight of West Sumatra Region and Cities}

This study uses cities of West Sumatra region in Indonesia as case study. This mountainous region lies on the western coast of Sumatra island which covers an area of $42297 \mathrm{~km}^{2}$. By 2014, the region's population was of 5131882 people, with an annual growth rate of $1.33 \%$. The population belongs mostly to the Minangkabau tribe of which Islam is the major religion. The main economic activities are agriculture, trade, services and small-scale industries. Moreover, there is a wide variation in the geographical conditions as well as employment structures across the region while some of the population works as fishermen or farmers and some others are engaged in the trade, the small scale industries and services. Such a geographical variation may influence the regional development process due to the different orientation of their major economic activities. The regional economic growth over the last fifteen years seems rather moderate and close to the national average, with an annual growth rate of about $5.2 \%$. 
The West Sumatra region has 7 cities of different sizes, their size ranging from less than 100 000 to almost 1 million people. The main urban economic activities are mostly in terms of small-scale industry, trade and services. The spatial structures of the cities vary either with respect to land areas or geographical conditions, as some cities lie in the coastal areas while some others in the mountainous areas. Padang is the capital city of the region which has the biggest total population of 889561 people in 2014, but its population density is still relatively low because its land area is quite large. But the city of Bukittinggi has the highest population density although its total population is still relatively low due to the very small land area. The city of Sawahlunto, on the other hand, has the lowest population density due to the relatively small population but on a large owned land area. Table 1 provides several general characteristics of West Sumatran cities for the year of 2014.

As a region of a developing country, the per capita income of West Sumatra region was still relatively low, i.e. about US \$2,198 in 2014, while poverty and unemployment are still a major economic problem. The economic performance at city level is more or less the same. Padang, as the capital city and the main business centre, has the highest per capita income as well as the highest rate of economic growth. Similarly, the city of Bukittinggi, as the main tourism centre within the region, has also a relatively high per capita income and economic growth. However, Pariaman is a newly established city, which still has a low per capita income and a poor economic growth. Other cities, such as Solok and Payakumbuh, also have lower per capita incomes, but they experienced a relatively high economic growth which suggests that these cities seem to have a promising future economic performance.

General Characteristics of West Sumatran Cities (2014)

Table 1

\begin{tabular}{|c|l|r|r|r|r|r|}
\hline No. & \multicolumn{1}{|c|}{ City } & $\begin{array}{c}\text { Total } \\
\text { Population } \\
\text { (People) }\end{array}$ & $\begin{array}{c}\text { Land } \\
\text { Area } \\
\mathbf{( K m}^{2} \text { ) }\end{array}$ & $\begin{array}{c}\text { Population } \\
\text { Density } \\
(\text { People/ } \\
\mathbf{K m}^{2} \text { ) }\end{array}$ & $\begin{array}{c}\text { Per } \\
\text { capita } \\
\text { Income } \\
\text { (US \$) }\end{array}$ & $\begin{array}{c}\text { Economic } \\
\text { Growth } \\
\text { Rates 2000 } \\
-\mathbf{2 0 1 4} \text { (\%) }\end{array}$ \\
\hline 1 & Padang & 889561 & 694,96 & 1280 & 3,148 & 6.57 \\
\hline 2 & Solok & 64819 & 57,64 & 1125 & 2,842 & 6.00 \\
\hline 3 & Sawahlunto & 59608 & 273,45 & 218 & 3,013 & 6.01 \\
\hline 4 & Padang Panjang & 50208 & 23,00 & 2183 & 3,288 & 6.07 \\
\hline 5 & Bukittinggi & 120491 & 25,24 & 4774 & 3,224 & 6.18 \\
\hline 6 & Payakumbuh & 125690 & 80,43 & 1563 & 2,251 & 6.47 \\
\hline 7 & Pariaman & 83610 & 73,36 & 1140 & 2,775 & 5.99 \\
\hline
\end{tabular}

Source: West Sumatra Local Government, West Sumatra Facts and Figures 2014, Padang 2015

\section{Results and Discussion}

Following the theoretical frameworks and methods of analysis described earlier, the first empirical result to be presented is in the form of the estimated quadratic regression results on the relationship between the average cost and the benefit cost functions with the population density. The use of population density as explanatory variable represents a special feature of this study since most of the previous studies used the total population as the independent variable. The optimal city size may then be estimated for each of the economic approaches used for these regression results. Table 2 presents the estimated average cost $(A C)$ and the average net benefit (ANB) as a function of the city population density $(P D)$. Data on the average cost used in this regression is the value of the city operational cost calculated from the realization of the local government budget minus the investment or the capital cost. The terms of operational costs in this study are referring to the annual expenses used to facilitate the 
operational activities of a city, such as wages and salaries, administrative expenses and maintenance costs. Investment costs are excluded from the operational costs because they can be utilized more than one year. In this case, the city operational cost is calculated by reducing the total city budged with the investment expenditures. Moreover, data on the number of the city population as well as the land area are absorbed from the figures provided by the city administration offices.

Table 2

Estimation of Quadratic Pooling Data Regression of the Average Cost and Net Average Benefit Equations of West Sumatra Cities (2001-2014)

\begin{tabular}{|l|c|c|}
\hline \multicolumn{1}{|c|}{$\begin{array}{c}\text { Independent Variables and } \\
\text { the Statistical Test }\end{array}$} & $\begin{array}{c}\text { Average Cost } \\
\text { Equation }\end{array}$ & $\begin{array}{c}\text { Average Benefit } \\
\text { Equation }\end{array}$ \\
\hline Intercepts & 2343048 & 1159779 \\
& $(7517)^{*}$ & $(26790)^{*}$ \\
\hline Population Density (PD) & -593.250 & 4004.636 \\
& $(-10.728)^{*}$ & $(32746)^{*}$ \\
\hline Squared population Density (PD $\left.{ }^{2}\right)$ & 0.121 & -1.038236 \\
& $(12.970)^{*}$ & $(-39104)^{*}$ \\
\hline Coefficient of Determination $\left(\mathrm{R}^{2}\right)$ & 0,712 & 0,986 \\
\hline Adjusted $R^{2}$ & 0,706 & 0,985 \\
\hline F-Statistics & 113.819 & 3280.557 \\
\hline Durbin Watson Statistics & 1.543 & 1.168 \\
\hline Number of Observations & 95 & 95 \\
\hline
\end{tabular}

Notes: Figures in the parentheses are t-statistics

*significant at 1 percent level

The estimated regression coefficient of $\alpha_{1}<0$ and $\alpha_{2}>0$ satisfies the u-shave curve of the average cost function. Similarly, the coefficients of $\beta_{1}>0$ and $\beta_{2}<0$ satisfy the inverse ushape curve of the net benefit function. This indicated that the two functions satisfy the mathematical necessary condition of both average cost and net benefit functions. Moreover, all of the regression coefficients of both the average cost and the average net benefit are significant either at $5 \%$ and $1 \%$ level. Such a high significant level of the regression coefficients is also confirmed by the high values of the F-statistics. The coefficients of determination are also quite high, ranging from 0.756 to 0.986 , which indicates that the population density is a suitable variable for the model. Moreover, the Durbin Watson Statistics lies between 1 and 2 which also indicates that the model does not contain a serious serial correlation problem. All of these statistical tests indicate that the estimated regressions are satisfactory for the statistical requirements.

Given the described regression results and following the equation (2) in the above methodology, we may then calculate the optimal city size in terms of population density instead of the total city population as mentioned in the Alonso-Richardson theoretical framework. For the minimum average cost approach, the calculated optimal city size is done by using the equation (2) where the optimal condition is a minimum AC. On the other hand, the maximum net average benefit approach is calculated by using the equation (3) where the optimal condition is when the slope of the $A B$ curve is equal to the slope of the AC curve. Finally, the long-run maximum profit approach is measured by using the equation (3) where the optimal condition is when the average cost is equal to the average benefit. 
Table 3 presents the calculated optimal city sizes for the seven cities in the West Sumatra region for each economic approach by using data from the year of 2001 to 2014 . So that, the figure for population density at the optimal city size measured under the minimum cost approach for West Sumatran cities is found to be of 2448 people/ $/ \mathrm{Km}^{2}$. Moreover, the optimal city size measured under the maximum net benefit is found to be a little bit greater, i.e. of 2507 people $/ \mathrm{Km}^{2}$. However, the optimal city size measured under the long-run maximum profit is found much greater than the former two optimal measurements of the city size.

Table 3

\section{The Measurement of the Optimal City Size of West Sumatra Cities Using Three Different Economic Approaches}

\begin{tabular}{|l|l|c|}
\hline Alternative Economic Approaches & The Optimal Condition & $\begin{array}{c}\text { Optimal City Size } \\
(\text { People/km }\end{array}$ \\
\hline Minimum Average Cost & Minimum AC & 2448 \\
\hline Maximum Average Net Benefit & Slope of AB = Slope of AC & 2507 \\
\hline $\begin{array}{l}\text { Long-run Maximum Profit (Zero Profit } \\
\text { Condition) }\end{array}$ & AC=AB & 4558 \\
\hline
\end{tabular}

Two interesting empirical findings can be explained. First, the optimal city sizes measured by the population density vary in accordance to the used economic approach. This finding confirms the earlier conclusion made by Camagni et. al (2013) that the optimal city size may not be a single one. Second, the finding is also accepted the Alonso-Richardson hypothesis that the calculated optimal city size for the minimum average economic approach is smaller than the net average benefit as well as the long-run maximum profit approaches. Moreover, the optimal city size based on the average net benefit is smaller than the long-run maximum profit approach. Third, the estimation of the optimal city sizes is found to be more suitable by using population density as the determining variable rather than the total population as proposed by Hitzckhe (2011), Camagni et al. (2013) and Kim et al. (2014). The use of population density as determining variable is quite important to be considered in a wide range of land areas of the city. It also influences the measurement of the optimal city size as well as its policy implications. Moreover, the population density is a relative index which enables us to compare the empirical results with those found in other regions or countries.

\section{Implications to Urban Policies}

The policy implications of the optimal city sizes may emerge in three aspects. First, related to the urbanization control policy for the cities, they may apply to cities which already have population density exceeds in relation to the optimal city size. Such a policy is important to avoid the existence of over-urbanization which might create several negative impacts such as urban poverty, traffic congestion, increasing unemployment and reduced environmental quality (Capello and Camagni 2000). Second, related to the environmental policy, the cities with a high population density might have some negative impacts with respect to traffic congestion, pollution, and other environmental quality. Third, related to the urban development strategy, cities may have problems either with respect to the city spatial plan or their development orientation. Table 4 provides the comparison of the current population density with the optimal city sizes under several economic approaches.

Urbanization Control Policy. With respect to urbanization control policy, the measurement of the optimal city size has an important policy implication. Such a policy is necessary for those cities that have a population density over the calculated optimal city size, such as Bukittinggi, although the total population in the year of 2014 is still rather small, i.e. of 120491 people. The reasons are that these cities have already experienced over-urbanization which may create some negative impacts to society life, such as a high unemployment rate as well as high 
poverty incidents (Sovani 1964). The city of Padang, on the other hand, does not need to implement the urbanization control policy, although its population has already reached 889561 people by the year 2014. Under the urbanization policy control, such possible negative impacts may be expected to be reduced in order to maintain a certain level of social welfare of the city. But for other cities in West Sumatra, the urbanization control policy may not be necessary yet because all of them, thus far, have not experienced over-urbanization.

Measured Optimal City Size in West Sumatran Cities Using

Table 4 the Three Economic Approaches (in Population Density)

\begin{tabular}{|l|c|c|c|c|c|}
\hline City & $\begin{array}{c}\text { Minimum } \\
\text { Cost } \\
\text { Approach }\end{array}$ & $\begin{array}{c}\text { Maximum } \\
\text { Net } \\
\text { Benefit } \\
\text { Approach }\end{array}$ & $\begin{array}{c}\text { Long-run } \\
\text { Maximum } \\
\text { Profit } \\
\text { Approach }\end{array}$ & $\begin{array}{c}\text { Population } \\
\text { density } \\
\mathbf{2 0 1 4} \\
\text { (People/ } \\
\left.\text { Km }^{2}\right)\end{array}$ & $\begin{array}{c}\text { Total Popu- } \\
\text { lation 2014 } \\
\text { (People) }\end{array}$ \\
\hline Padang & $\mathrm{U}-\mathrm{u}$ & $\mathrm{U}-\mathrm{u}$ & $\mathrm{U}-\mathrm{u}$ & 1280 & 889561 \\
\hline Solok & $\mathrm{U}-\mathrm{u}$ & $\mathrm{U}-\mathrm{u}$ & $\mathrm{U}-\mathrm{u}$ & 1125 & 64819 \\
\hline Sawahlunto & $\mathrm{U}-\mathrm{u}$ & $\mathrm{U}-\mathrm{u}$ & $\mathrm{U}-\mathrm{u}$ & 218 & 59608 \\
\hline Padang Panjang & $\mathrm{U}-\mathrm{u}$ & $\mathrm{U}-\mathrm{u}$ & $\mathrm{U}-\mathrm{u}$ & 2183 & 50208 \\
\hline Bukittinggi & $\mathrm{O}-\mathrm{u}$ & $\mathrm{O}-\mathrm{u}$ & $\mathrm{O}-\mathrm{u}$ & 4774 & 120491 \\
\hline Payakumbuh & $\mathrm{U}-\mathrm{u}$ & $\mathrm{U}-\mathrm{u}$ & $\mathrm{U}-\mathrm{u}$ & 1563 & 125690 \\
\hline Pariaman & $\mathrm{U}-\mathrm{u}$ & $\mathrm{U}-\mathrm{u}$ & $\mathrm{U}-\mathrm{u}$ & 1140 & 83610 \\
\hline $\begin{array}{l}\text { Estimated Optimal } \\
\text { City Size (People/ } \\
\mathrm{Km}{ }^{2} \text { ) }\end{array}$ & 2448 & 2507 & 4558 & & \\
\hline
\end{tabular}

Notes: $U-u=$ Under Urbanization

$\mathrm{O}-\mathrm{u}=$ Over Urbanization

Urban Long-term Development Policy. Every city may have a different long-term development objective depending upon the economic, social and political purposes. Some cities may intend to pursue the objective to become a centre for government administration activities, and some others may intend to pursue the objective to satisfy the needs of their inhabitants. But, there are also many cities expected to be sufficiently large business centres to maximize the regional economic growth. Each of these long-term urban development goals certainly require different optimal city sizes to support their necessary economic and social needs.

Given such a different urban long-term development orientation, it seems to be useful to coincide it with the measurement of optimal city size. If the interest is just of the government administrative centre, then the relevant development orientation would be the minimum operational cost for the city. This implies that the optimal city based on the minimum cost approach seems to be more suitable for a development orientation. But, if the development objective is more related to the maximum social welfare of the urban population, then the average net benefit approach seems to be more suitable, and the optimal city size should be higher. However, if the main objective is to become a business city, then the maximum long-run profit approach would be more suitable and the optimal city size should be big enough to create sufficient demand for business expansion activities. Therefore, the optimal size for this city should be larger than those for the city size under the minimum cost and maximum net benefit. Moreover, if environmental quality is also considered within policy objectives, then the actual city size should be smaller than the optimal size.

Urban Environmental Policy. Finally, the measurement of the optimal city size gives also important implication to the environmental policy. Another important implication of the optimal 
city size is with respect to efforts in maintaining the urban environment quality. The city, whose population density is above the calculated optimal city size, such as Bukittinggi city, should have a very tight control of the environmental quality. Such a policy is quite important to be able to maintain a certain level of the city environmental quality. But for that city which still has a population density below the optimal city size, it may have a rather easy control on the urban environment quality, although the total population has already been close to one million people such as the city of Padang. Environmental control policy will depend upon the type and degree of the externalities experienced by the city as well as the existing regulation in the country.

\section{Conclusion}

This study measures the optimal city size from the three economic points of view: minimum operational cost, maximum net benefit and maximum long-run profit. Each economic approach may give different measurements of the optimal city size as well as its implications to the urban development policy. This confirms the results of the previous study made by Camagni et al. (2013) that the optimal city size may not be of a single measure. Moreover, the previous studies conducted by Camagni et al. (2013) and Kim et al. (2014) have already considered the first two approaches, i.e. the minimum cost and net benefit in the measurement of the optimal city size. Our present study extends the analysis to include the long-run maximum profit condition within the measurement of the city size which is quite important if business and economic growth become the main orientation of the urban development policy.

Unlike most of the previous studies, the optimal city size in this analysis is measured in terms of population density rather than of total population. The use of population density is considerably important to take into account the large variations in size of land areas and geographical conditions which also significantly influence the measurement of the optimal city size. Moreover, population density is a relative index which enables us to compare the empirical results with the related studies conducted in other regions or countries.

Due to a lack of available time series data for each city, the regression estimation in this study was conducted by using the pooling data system which gives a single measurement for the West Sumatra region and it represents the average values for all cities in the region. Ideally, the regression estimation should be conducted by using the time series method to get a single measurement of the optimal size for each city. This effort may be considerably important since the variations of land area, the geographical conditions, as well as the function and hierarchy of the city represent quite large challenges. Addressing all of them would be also our challenge for further research, in order to get a better measurement of optimal city sizes.

\section{References}

ALONSO W. (1971), The Economics of Urban Size, Papers in Regional Science 26 (1),

ARNOTT R. (1979), Optimal City Size in a Spatial Economy, Journal of Urban Economics 6 (1), 65-89.

ARNOTT R. J., STIGLITZ J. E. (1979), Aggregate Land Rents, Expenditure on Public Goods, and Optimal City Size, The Quarterly Journal of Economics 93 (4), 471-500.

BEGOVIC B. (1991), The Economic Approach to Optimal City Size, Progress in Planning 36, 93-161.

BURNETT P. (2016), Overpopulation, Optimal City Size and the Efficiency of Urban

Sprawl, Review of Urban \& Regional Development Studies 28 (3), 143-161.

CAPELLO R., CAMAGNI R. (2000), Beyond Optimal City Size: An Evaluation of Alternative Urban Growth Patterns, Urban Studies 37 (9), 1479-1496.

CAMAGNI R., CAPELLO R., CARAGLIU A. (2013), One or Infinite Optimal City Sizes? In Search of an Equilibrium Size for Cities, Annals of Regional Science 51, 309-341. 
HARRIS T. F., loannides Y. M. (2000), Productivity and Metropolitan Density, Tufts University, Retrieved from: http://ase.tufts.edu.

HITZSCHKE S. (2011), The Optimal Size of German Cities: An Efficient Analysis Perspective, Darmstadt Discussion Papers in Economics 202, 1-21.

KIM E., HEWINGS G., NAM K.-M. (2014), Optimal Urban Population Size: National vs. Local Economic Efficiency, Urban Studies 51 (2), 428-445.

MARQUES R. C., KORTT M. A., DOLLERY B. (2015), Determining of the Optimal Size of Local Government: The Case of Tasmanian Councils, Australian Journal of Public Administration 74 (2), 212-226.

MIZUTANI F., TANAKA T., NAKAYAMA N. (2012), Estimation of Optimal Metropolitan Size in Japan, with consideration of social costs, Empirical Economics 48 (4), 1713-1730.

RICHARDSON H. W. (1978), Urban Economics, Dryden Press, Hinsdale, IL.

SOVANI N. V. (1964), Analysis of "Over-urbanization", Economic Development and Cultural Change 12 (2), 113-122.

YARMOHAMMADIAN N., AKBARI N., ASGARY A., MOVAHEDINIA N. (2014), Optimal and Sustainable City Size by Estimating Surplus Function for Metropolitans of Iran, International Journal of Business and Development Studies 6 (1), 21-38.

Initial submission: 16.11.2015

Revised submission: 03.10.2016

Final acceptance: 05.12.2016

Correspondence: Faculty of Economics, Andalas University, Kampus Limau Manis, 25163

Padang, Indonesia

Email: syafrizal17@yahoo.com 
